ancommon; they occur, of course, at long ranges or from cicochets. They are usually fatal but not always so. The case has an additional interest from the fact that the injury was inflicted by a soft-nosed Mauser bullet.

CASE 6.-The patient, a private, was wounded in a minor engagement near Vereeniging and on the evening of the third day was admitted to the military hospital at Flandsfontein. A small circular wound of entrance could be seen over the prominence of the right malar bone, below and in a line with the outer canthus. No exit wound could be found and the bullet had clearly lodged in the cranial cavity. There was complete paralysis of the right arm and leg but no paresis of the face. The pupils were equal and reacted sluggishly to light. The patient was semi-conscious, presenting signs of advancing compression. On the next morning trephining was performed over the middle of the left motor area. The dura mater bulged and did not pulsate; it was therefore incised. The brain protruded somewhat. After the escape of a considerable quantity of blood pulsation returned. Search was then made with the probe for the bullet but it was not located. The patient died on the following morning early on the fifth day after receipt of the wound.

A post-mortem examination was made to determine the coarse and location of the bullet. The probe could be readily passed through a channel leading from the entrance wound through the right malar bone and the body of the sphenoid bone. Crossing the middle line the bullet track entered the cranial cavity in the middle fossa. There was no gross fissuring of the base and the channel through the bone was of small diameter. The bullet had then apparently impinged against the anterior surface of the petrous portion of the left temporal bone about its middle, at which point a small portion of lead was found. It had then been deflected directly upwards towards the vertex, producing a lacerated track in the brain substance. This entered the under surface of the anterior portion of the left temporo-sphenoidal lobe, not, however, appearing on the surface of the brain till it emerged at the vertex one and a half inches from the midale line. At this point a small puncture in the dura mater showed that the bullet had impinged against the skull.

had then been again deflected backwards and downwards through the substance of the ascending frontal and parietal convolutions. It was found lying at the middle of the latter very close to the operation wound. The ascending track was about an inch in diameter at its lower end ; the descending track was smaller.

This case presents several features of interest. It was caused by a soft-nosed Mauser bullet, one, that is, in which the point of the nickel sheath had been removed to the extent of a quarter of an inch, leaving the tip of the leaden core exposed and projecting. Such a bullet is of the "expanding" type, of which a good deal has been heard during the war. Nevertheless, it did not "expand," although it had drilled the malar and sphenoid bones and impinged against the dense substance of the petrous bone. The only distortion which it suffered was that the projecting leaden tip had been completely shorn off transversely at the point where the nickel sheath erded, presenting an appearance quite different from slue olique shear of a ricochet. As a consequence the venecrative power of the bullet was so reduced that it did not pass out of the cranial cavity, but being twice deflected by contact with the bone and altered in shape produced a very extensive laceration of the brain tissue which was the cause of death. Had the bullet been a normal Mauser it would at a medium range have completely perforated the cranial cavity; the injury to the bone would have been more grave but the laceration of the brain would have been less extensive. The question of exploratory operation which arines in such cases must depend for decision on the indicridual circumstances of each case. Should, as in this instance, localising symptoms render it probable that the bullet is lying in a situation accessible to the surgeon its removal should certainly be attempted.

Johannestorg.

New Operation Theatres at Bradford Royal TNFIRMARY. - Two new operation theatres provided at the Bradford Royal Infirmary by the generosity of Mr. Harrison Benn of Holcombe Hall, Dawlish, South Devon, were opened on Oct. 10th by Viscount Mountgarret. The instruments and furnishings were the gift of. Mr. W. H. Longbottom, of Myddleton Hall, Ilkley.

\section{MENTAL DISSOLUTION THE RESULT OF ALCOHOL. ${ }^{1}$}

By ROBER I JONES, M.D., B.S. LoND., F.R.C.S. ENG., PHYSICIAN ANI SUPERINTENDENT OF THE LONDON COUNTY ASYLUM, CEAYBURY.

WHEN, at the request of its able President and my old friend Dr. Harry Campbell, I consented to read a paper before the Society for the Study of Inebriety I felt the limitation of my experience in regard to the subject of inebriety, as ordinary cases of intemperance do not come under my care. My knowledge is derived from those in whom the vice of intemperance has become a disease, manifested by a craving over which a normal will has no control and resulting in acts which do not recognise submission to authority and which are judged to be irresponsible. The persons to whom I refer form only a small part of the multitude who indulge in strong drink, but they are by no means a small proportion of those who are admitted into asylums and who thereby sacrifice two objects so dear to self-respecting men-viz., their liberty and their legal franchise.

Many distinguished writers and persons of much authority and ability, too numerous to mention, have expressed themselves before your society upon this great question of drink, and its philosophical, medical, social, and economic aspects have been presented and discussed, but, not recently at any rate, have the effects of alcohol in relation to the production of insanity been submitted to its notice, for I have observed no such record in its proceedings of late years. If my paper fails to be of interest I trust that the President of the society may not be altogether exempt from the rebuke which in other circumstances would have been mine.

\section{The Distribution of Alcohol.}

Of all poisons, possibly alcohol is the most universal and the most widely diffused in nature, for it is found wherever destruction of organic matter by the various agents of fermentation takes place; and it is almost impossible to avoid it. We breathe it in the air, we drink it at the bubbling spring, and eren when we die we are laid in alcoholic earth. Like many other poisons it is from its stimulating properties of distinct service to mankind, and although its physiological action has given rise to much acrimonious debate the consensus of opinion among medical men in the present day is that in many instances, under the control of the reasoning and moral taculties, its use is to some extent beneficial, and therefore let those who find it so and who can strictly limit its consumption enjoy the benefit. To others, on the other hand, alcohol is a lethal weapon which works its fell effect, and therefore let those who are so affected abstain altogether from its use. It affects the weakly by reducing their energy, their vigour, their initiative, and their enterprise. It is from the indiscriminate use of alcohol by this class that disease, degeneration, crime, and brutality result. in consequence of which wise and tolerant men who have found even benefit from it in moderation have totally abstained from it and decried it in no measured terms as the most potent evil and the most active cause of sickness, disease, and death. This being so, it has been asked, "Why do men drink?" and the general answer, we are bound to confess, is, as Shadwell states, that alcohol in one form or another exhilarates, removes depression, lightens pain, and makes glad the heart. It tends to foster conviviality and good fellowship, to make life brighter and more enjoyable, and to make man pleased with himself and others.

\section{General EFFects of Alcoholism.}

As to the general effects of alcoholism-if the term be applied to the whole range of disorders caused through poisoning by alcoholic liquors-the toxic action may be described as either direct upon the individual or social, far-reaching, and indirect, affecting the efficiency of the community and causing injury to the national reputation through a loss of productive labiur, an increase of pauperism, the spread of crime, and the retardation of all improvement. Through the direct influence of

1 A paper read ibefore the Society for the Study wof Inehriety on. 
excessive drink, which is the main theme of my remarks and to which I shall return, definite changes occur in the nervous tissues as well as in the vascular and glandular tissues, which involve premature senility, debility, and decay; a destruction of mental vigour and capacity, extinction of all moral and religious principles, an excitation of all the worst passions, and an indescribable degradation. It is owing to these profound but preventable changes that moralists, philanthropists, and others have agitated for reform. They are staggered by the fact that although our own country has progressed and is in advance of others in regard to religion, the arts, science, and all that tends to liberty and makes for the freedom we call civilisation, it is now consuming at the present time more alcohol in proportion to the population than it has done in any year for the last 20 years and this in spite of increased education and improved sanitary and social conditions. But to these reformers it may be some, though small, consolation that although the English people are the freest entertainers in the world, whether on the highest or lowest scale-whether from the rich man's cellar or in the form of the "one pot more" pressed by one thriftless labourer upon another-the English people drink less per head than those of France, Denmark, Belgium, Switzerland, or the German Empire, arranged as these are in their respective gradations. The fact, however, still remains that in one year (1898) the cost of alcoholic drinks consumed in this country alone amounted to the extraordinary total of $£ 154,480,934$, or $£ 316 s .10 \frac{1}{2} d$ : per head of the population. During this same year 31 gallons of beer per head of the population were consumed and the revenue from beer, which was then over $£ 12,000,000$, has continued to rise until in 1900 nearly $£ 13,750,000$ were received. A still more striking fact is that the deathrate from alcohol during the last 15 years has increased by 42 per cent. in mer and 100 per cent. in women, having reached a total in 1900 of 91 per $1,000,000$ for men and 52 for women-a mortality more numerous per $1,000,000$ from alcohol in some large towns, such as Liverpool, than that due to scarlet fever and all other zymotic disease taken together. In areas of excessive disease and mortality which are engaging the attention of the local justices and the medical officers of health it is found that public-houses are over-supplied. Surely it is time that some check should be placed upon the power of the working-man to drink his pockets empty, his health away, and his mind imbecile, and thus to become a hopeless burden upon the community. It is time that the destructive effects of alcohol upon health in the class under consideration should be pointed out with a bold hand. however painful they may be to witness and to describe. We need something more than our climate to furnish the excuse, and our convivialities to furnish the tradition, for our intemperance.

\section{Statistics of Alcoholism and INSANity.}

There are probably at the present time no less than 110,000 certified insane persons in England and Wales alone, of whom approximately about 50,000 are males and 60,000 are females. If the Lunacy Commissioners' Blue Book for England and Wales for 1901 be consulted the proportion per cent. of instances in which alcohol has been assigned as the cause of insanity to the yearly average number admitted into asylums in the five years 1895-99 inclusive is 21.8 for males and 9.5 for females-the proportion is much higher in Scotland; and after allowing for the deaths of those whose form of insanity is more immediately fatal than those cansed by alcohol there are, I believe, upon the lowest computation remaining in asylums at the present time no less than 10,900 males and 5800 females who are mentally decrepit thruugh the effects of alcohol. During the time that the London County Council's Asylum at Claybury has been opened, from 1893 to the end of 1901 - a period of less than nine years-8493 patients ( 3776 males and 4717 females) have been admitted thereto, of whom $21 \cdot 2$ per cent. of the males and $12 \cdot 6$ of the females were definitely ascortained to owe their insanity to drink. A total of over 800 men and 594 women have been thus rendered incapable of productive work through their own acts and are being, or have been, supported and clothed at the ratepayers' expense.

The proportion of women whose insanity is ascertained to be due to drink is higher in Claybury than any of the other six asylums of London, possibly owing to the fact that it is the territorial asylum for the Eastend of London, where so many women are employed in factory work. It is also a fact that in the city of Nottingham, where so many women are employed in the lace factories, twice as many women as men are received into the asylum whose insanity is due to drink. In Sunderland, on the other hand, where the prosperity of the mechanic and the miner is evidenced by high wages and abundant work-and here, also, the question of climate and occupation may have to be considered-the proportion among men reaches 38.6 per cent., as compared to 21.4 per cent. among women, which yields a combined average of 30 per cent. In marked contrast witb this is the case of Corn wall. which for men and women gives the combined average of 2 per cent., and of rural Kent, which gives a combined average of 3.8 per cent. For the whole of London during the same period (1893 to 1901), 2662 men and 1677 women were received into its asylums who owed their insanity to alcoholic intemperance, and it is a painful and sad reflection that every year in London nearly 600 persons (400 males and 200 females) become inmates of pauper asylums from this cause alone. The misery and cruelty resulting to the family and the absolute degradation of the home, as the result of intemperance, are too well known to my hearers to need description or reference, quite apart from the great loss to the community through unproductiveness at a craft or trade caused by the detention of the bread-winner in an asylum. The fact pointed out by the Lunacy Commissioners, that whereas the proportion per cent. of alcoholic admissions to total admissions into asylums bears a ratio in the private class of 20.8 males and 9.4 females it is 22.7 for males and 9.7 for females among the pauper class, seems to show a greater moral weakness, which prefers immediate gratification to ultimate good, among the poorer classes, as also does its how the increased inhibition which education, the influence of public opinion, and the effects of social ostracism may exercise upon the well-to-do. There is probably less drinking in proportion among the well-to-do than among the poor who are certainly more prone to alcoholic insanity and more likely to yield to facilities for temptation. It is a fact which cannot be blinked that secret drinking is more common among women than men and more corumon among well-to do women than among the poor. To a great extent the grocers' licence, now about to be curtailed, may account for this form of self-indulgence.

\section{SPECIAL EFfects of ALCOHOL.}

The effects of alcohol upon man vary with the dose and the length of time during which the habit has prevailed. My experience deals in the main with its more chronic and persistent effects as seen in the insane, and the symptoms vary. frum general functional changes to the most aggravated forms of paralytic dementia. Acute alcoholic insanity, of which we in asylums see comparatively little, presents a rapid course and a short duration. It is the form of mental derangement due to a toxic cause which is soon eliminated, after which the organism readjusts itself and the individual recovers. Chronic alcoholism, on the other hand, implies an altered nutrition of all the tissues, particularly parenchymatous elements and epithelium such as that of the bloodvessels, causing thickening and ultimately fibroid changes. It has been stated to be one of the special causes of dementia paralytica. It certainly is one of the important elements in the strain which predisposes to this breakdown and is a most fertile source of nervous diseases.

The degeneration of the tissues-nervous and non-nervous - consequent upon altered nutrition is so general and farreaching that the resulting symptoms are of a most protear nature. Attempts have been made to differentiate these according to the particular form of alcohol taken-such as wines, beer, spirits, liqueurs (absinthe), \&c., but the di tinction is less peychical than physical and the symptoms consist in the greater frequency of convulsive discharges from such as absinthe, of analgesia from wines, and of hyperalgesia from escences. The liver of the spirit-drinker is familiar, as also the gross fatty changes in beer-drinkers. These latter changes are, however, more common in the experience of hospital than of asylum physicians.

MODIFYING FACTORS.

Many different considerations present themselves in regard to symptoms. The following are instances. 1. The diathesis, idiosyncrasy, or inheritance of the individual. Ar inheritance of insanity or nervous disorders is found in about from 25 to 33 per cent. of all such cases admitted into asylums. person of neurotic inheritance, as evidenced by in:anity. epilepsy, or other neuroses in the ancestors, is predisposec 
to the incidence of delirium, small doses of alcohol giving rise to marked mental instability and other functional disturbances; in others the nervous system almost entirely e-capes and the stress is felt upon the liver. kidneys, or other organs. 2. Sex appears to have a marked influence, for although alcoholic indulgence is most common among men, women recidivists are more common and women are less curable. 3. Elimination is a personal factor dependent upon the activity of the various excretory organs, such as the skin, kidneys, lungs, \&c., in any particular individual. 4. Exercise appears also to influence the symptoms, as life in the open air favours tolerance. Both men and women of sedentary habits suffer in comparison to the more active and the more frequent incidence of peripheral neuritis in women is probably due to their indoor life. 5. Age is a modifying factor. The period of greatest incidence to the pernicious effects of alcohol corresponds closely with that y,eriod upon which falls the greatest mental strain. Males tetween 25 and 30 years of age and those between 35 and 40 years appear (according to Bevan Lewis) to be more ?usceptibie to alcohol than those of any other age. The former is a period peculiarly characterised by intellectual advance and one during which the habits tend to become independent and fixed; the other is an epoch during which the struggle for existence makes itself felt in fullest force and it is also an age during which, as Lewis points out, the feeble and indifferent organisms often feel the want of artificial stimulus, to the use of which they often succumb. It is important in the interpretation of observed facts to note the modifying factors above stated; still, it may be said that alcohol acts preferentially upon the brain. It is also noteworthy that some time after alcohol has ceased to be taken, even after some months, its mental effects may vividly appear.

\section{SYMPTOMS OF ALCOHOLIC INSANITY.}

The symptoms of alcoholic insanity may best and most conveniently be classified according to the nervous or other territory invared and they may be divided into sensory, motor, and intellectual, the functional changes arranging them:elves in the order shown by Hughlings Jackson to be inver=e of their evolution, the last developed and the most highly evolutionised being the first to be dissolved. Mentally the higher states of consciousness, such as discrimination, judgment, and association, are generally the first to be impaired in alcoholism. By the loss of inhibition and control caused through the destruction of the higher level the activities of the lower rise into consciousness and become prominent if not obtrusive. Impairment of association is evidenced by the retarded reaction to sensory, visual, and auditory stimuli. An interesting table has been prepared by the Professor of Experimental Psychology in King's College (Dr. W. G. Smith) in the laboratory at Claybury Asylum under the direction of Dr. F. W. Mott, showing the comparative results of reaction in normal cases (members of the staff) and those whose insanity was due to alcholism.

Table showing the Oral Reproduction of Auditory Impressions, being a Test of the Memory in Normal and Aleoholio Mental cases.

Normal and pathological percentages.

\begin{tabular}{|c|c|c|c|c|c|c|c|c|c|}
\hline \multicolumn{3}{|c|}{-} & \multicolumn{6}{|l|}{ IV. } & X. \\
\hline $\begin{array}{l}\text { Normal } \\
\text { group }(9 \\
\text { persons). }\end{array}$ & $\begin{array}{l}(a) \\
(b) \\
(c)\end{array}$ & $\begin{array}{l}\text { Rightly placed. } \\
\text { Wrongly placed. } \\
\text { Omitted. }\end{array}$ & $\left|\begin{array}{r}97 \cdot 8 \\
0 \cdot 3 \\
1 \cdot 3\end{array}\right|$ & $\begin{array}{r}934 \\
0.4 \\
3 \cdot 0\end{array}$ & $\left|\begin{array}{r}83 \cdot 7 \\
2 \cdot 0 \\
7 \cdot 7\end{array}\right|$ & $\begin{array}{c}73 \cdot 5 \\
3 \cdot 4 \\
11 \cdot 9\end{array}$ & $\begin{array}{r}65 \cdot 3 \\
6 \cdot 3 \\
18 \cdot 8\end{array}$ & $\left|\begin{array}{c}49 \cdot 9 \\
10 \cdot 6 \\
26 \cdot 1\end{array}\right|$ & $\begin{array}{l}47 \cdot 1^{*} \\
11 \cdot 2 \dagger \\
30 \cdot 7+\end{array}$ \\
\hline $\begin{array}{l}\text { Alcoholic } \\
\text { group }(5 \\
\text { persons. } 3 \\
\text { male. } 2 \\
\text { female). }\end{array}$ & $\begin{array}{l}(a) \\
(b) \\
(c)\end{array}$ & $\begin{array}{l}\text { Rightly placed. } \\
\text { Wrongly placed. } \\
\text { Omitted. }\end{array}$ & $\mid \begin{array}{r}91 \cdot 3 \\
03 \\
63\end{array}$ & $\begin{array}{r}82 \cdot 2 \\
2 \cdot 4 \\
8 \cdot 4\end{array}$ & $\begin{array}{r}66 \cdot 5 \\
48 \\
18 \cdot 5\end{array}$ & $\begin{array}{r}55 \cdot 5 \\
8 \cdot 0 \\
25 \cdot 4\end{array}$ & $\begin{array}{l}40 \cdot 8 \\
12 \cdot 9 \\
37 \cdot 8\end{array}$ & $\begin{array}{l}28 \cdot 6 \\
17 \cdot 1 \\
47 \cdot 3\end{array}$ & $\begin{array}{l}27 \cdot 0 \\
14 \cdot 4 \\
49 \cdot 0\end{array}$ \\
\hline
\end{tabular}

Letters reproducer quite correctly.

$\lceil$ Letters reproduced from presented series in quite wrong order. I Letters omitted from the presented series.

A series of experiments involving the calling out by the experimenter of it number of letters trom 4 to 10 . Each vertical series under Roman numerals shows the number of letters presented in each set of experiments and the percentage results. The letters were spoken by the experimenter at an even rate determined by the metronome beating 708 per minute.

Apperception, whereby experience of the past is called up and compared with the present, is affected, so that a condition which has been termed "paramnesia" results-a state of mind in which the patient is oblivious to his present environment but picks up circumstances from his recent past and discusses them in the light of his present environment. This, which is one of the most pathognomonic signs of chronic alcoholism, will be further referred to. The obliviousness is due probably to an impairment of that special quality of nervous matter, that power of receiving and fixing impressions, that plasticity whereby memory or retentiveness becomes possible. The condition termed "paramnesia"--an inability to orientate, to remember place or time-is exemplified by the inability which such patients have of concentrating their attention and thoughts upon passing events. They wander mentally and they believe themselves to have made imaginary journeys, to have ridden in omnibuses and cabs, to have travelled in trains, to have visited their neighbours, or to have been engaged at work when, as a matter of fact, they have been bedridden the whole time. Owing to an increased cerebral erethism there is a busy delirious restlessness and yet from the want of discrimination and the failure of association there is a loss of that power of "focussing" in the brain and patients will greet as an old acquaintance a person whom they have never before met. They imagine others in the ward to be their relatives and there is marked mental confusion which they themselves fail to appreciate. All this is in accordance with the doctrine already quoted that delusions have for their subject some very recent avocation, interest, or association, because the last evolved structure of the cortex is the first to be affected in dissolution, hence the bringing up and reference to events in the recent past and the attempts to fit them to the present. Owing to the prominence of what have been described as lower level functions in consequence of dissolution of the higher inhibitory level, irritability of temper, garrulity, and licence become apparent. A chavge in the moral character and conduct of the individual may result and he may offend against public decency and the whole moral and intellectual nature may become blunted and the will enfeebled. Restless, purposeless, even violent sensorimotor disturbances occur, the sensory disturbances generally arranging themselves bilaterally, and advancing from the periphery to the centre. In the skin the sensory disturbances take the form of perversion, an exaggeration or a diminution of the normal sensation. On the motor side tremor is a marked phenomenon and ends not infrequently in distinct epileptiform seizures. These sensori-motor disturbances form the groundwork of various hallucinations and delusions. I have several times sent out alcoholic patients recovered who were received into the asylum as epileptics in consequence of alcohol. During their detention, when alcohol was compulsorily withdrawn and unobtainable, they have lost their fits but have relapsed after leaving the asylum upon resuming alcohol and in consequence they have had to be readmitted. The discharge of sensori-motor centres in extreme cases of chronic alcoholism may be followed by great exhaustion indicated by paralysis on the motor side and by reduction or loss of consciousness amounting to coma on the mental side. Upon the withdrawal of the accustomed stimulant in less pronounced cases of drink the feeling of exhaustion may become so acute a dimcomfort that a special and urgent want is felt throughout the whole organism. This amounts to a veritable craving --a condition denied by some writers-and the victim of indulgence is absolutely unable to make any exertion until the craving has been appeased by providing further stimulant. That this craving exists is the experience of all those who have seen a large number of alcoholic cases. It is so overpowering that ordinary volition is absolutely impotent to resist it, and it is regardless of all altruism and takes no beed of the warning or the appeal of parent, husband, wife, or offspring Jennings of Paris describes this craving in cases of morphia, and he points out a peculiar "tableau" or flattening of the pulse, due to a want of tone which disappeared when the patient was assuaged with another dose of morphia. I append herewith a sphygmographic tracing of a pulse taken by Dr. Bolton and myself in a case of alcoholic dementia with peripheral neuritis a few days after the deprivation of alcohol (Fig. 1), and one which shows the effect upon the pulse when the craving had been satisfied by its administration (Fig. 2), indicating, so far as can be ascertained, a definite physical basis for the craving.

As to the nature of alcoholic affections, their impulsiveness is notable, and whether mental or sensori-motor they are of an essentially spasmodic or convulsive character. They are sudden and violent, their mania is often destructive, brutal, 
and irrepressible, and is often attended with terror-a condition which has been described as panophobia. Patients may turn against others or against themselves and they are generally dangerous and aggressive. The great tendency in alcoholic mental affections is to experience hallucinations, not only of sight and of hearing, but also of the visceral and systemic organs. In the latter they imagine that their hearts are dragged out, their lungs are injected with -mercury and corrosives, or their stomach is full of serpents, batteries, babies, or cricket balls. Their food is drugged,

Fig. 1.

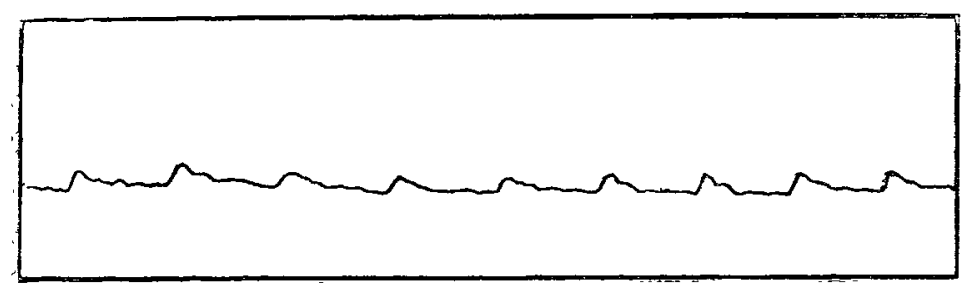

Alcoholic neuritis. May 19th, 1902, 3.15 P.M.

FIG. 2.

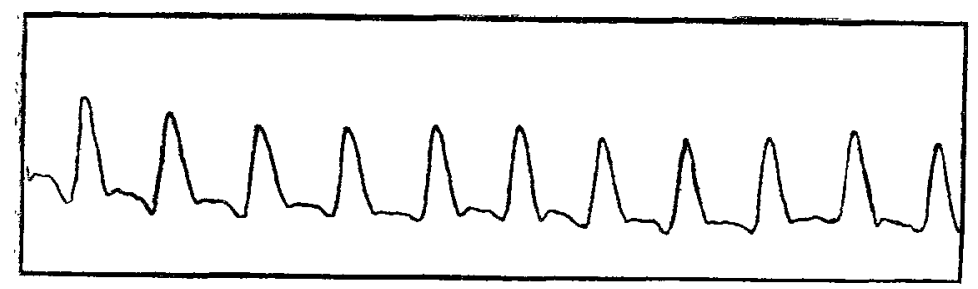

Same patient 15 minutes later, after half an ounce of brandy.

filthy refuse is thrown over them at night, devils, electrical machines, and mysterious agencies play upon them, their enemies read their thoughts, and their best friends curse and hate them. Occasionally delusions of grandeur and exaltation are experienced, but these delusions fail in the benevolence of the general paralytic and unlike the delusions of general paralysis are not altruistic; their delusions are also more fixed and the tendency throughout is to be suspicious and distrustful and the victim of malignant fear and persecution. It is not improbable that the patient feels the increased specific resistance of his nervous tissues and in consequence develops a feeling of distrust against his environment

The forms of insanity apart from the acute disturbances (mostly functional) which result from alcohol are (1) amnesic, (2) delusional, and (3) chronic varieties which end in dementia. They need not be considered within the scope of this paper.

\section{Pathology of Chronic Alcoholism.}

As to the morbid changes in alcoholism, I have been favoured by Dr. Mott with microscopic specimens characteristic of the lesions in the higher nerve centres and these serve also to show the difference between alcoholic insanity and general paralysis. The naked-eye appearance of the cerebral convolutions in both forms exhibits cedema with more or less wasting, but there are no granulations of the ependyma in alcoholic insanity. In long-protracted cases of the latter there may, as in cases of general paralysis, be signs of chronic meningo-encephalitis, the pia-arachnoid membranes being thickened, opalescent, or opaque, and containing microscopically numerous young connective tissue cells. In both diseases the vessels are dilated and the peri-vascular spaces distended, but in cases of general paralysis these spaces are most often crowded with pavement-like epithelial cells. There may be small hæmorrhages scattered through the cortex and these are not uncommon in cases of acute alcoholism, being due to venous engorgement with cardiac failure. Recent red softening is also not uncommon in patches. They are probably the causes of the twitching, tremors, paralysis, or anæsthesia observed. In the grey and white watter there is an excess of neuruglia vells, and the larger pyramids are shown to exhibit chromatolysis, the Nissl granules having disappeared completely in some of these, the cells being diffusely and uniformly stained and, what is a further characteristic, their processes lost. The nucleus is swollen and the nucleolus is eccentrically placed within the nucleus as the latter is within the cell. The outline of the cell is roundish and the cells are swollen and turgid; irregular leucocytes are also seen adhering to them and the pericellular spaces are dilated. The mediumsized pyramids present slighter chromatolysis, the smaller pyramids are swollen, and the nucleus is eccentric. The molecular layer in the specimens shows increased neuroglia cells with large nuclei. Marchi staining shows degenerate fibres beneath the large pyramids and Marchi-Pal staining shows a diminution in the number of the superficial tangential fibres. The large multipolar cells of the cord are similarly affected to those in the cortical motor area, and there are markedly degenerate fibres in the posterior column. The cerebral and spinal cells are affected singly or in groups, and close to degenerated cells may be seen healthy ones unchanged, showing a peculiarly selective action upon one or a group. of cells by the alcoholic poison. In other organs marked degeneration occurs, even the voluntary muscles undergoing acute fatty changes.

Now the changes above described implicate especially the neurons of the cortical area-an area which is physiologically described as psycho-motor-and the resulting impairment is, as we have seen, a paresis of the motor mechanism and a retardation of mental reaction with a tendency to explosive impulses, psychical and motorial. Taking the motor side first, there is in the alcoholic a marked motor impotence with tremor caused by irregular contraction of antagonistic muscles. If in nerve preparations an efferent nerve is etherised and a central stimulus is applied, muscular contraction is impaired or absent (Gotch). In alcoholic cases the effect of the alcohol taken may possibly be similar, an increase of the specific resistance of the nerve trunk occurring, and this together with a defective innervation of nerve centres-unless nerve-shocks are sufficiently forcible-tends to check a regular discharge which in consequence becomes interrupted and irregular and gives rise to a motor and psychical tremor. As to the forgetfulness, we have in the breaking-up and disappearance of the processes of nerve-cells an anatomical and pathological explanation. The different protoplasmic processe: arborise with each other and are stated to be capable of direct contiguity (but not continuity) at one or many points, the presumed retraction of these processes during consciousness cutting off in mental health the great majority of inter-neuronic connexions and allowing nervous currents to travel with increased strength over a few fibres, rather than a diffusion of current with consequent mental confusion as presumably happens in disease over many fibres.

This suggestion of the method by which nerve currents travel has engaged the earnest attention of many physiologists-conspicuously that of Lugaro in Italy-but at best it is only an approximate hypothesis. It is certain, however, that the various neurons of association which in the tangential fibres of the cerebral cortex undergo atrophy in direct proportion to the depth of the dementia have to carry various impressions which connect the different centres in the brain; and when these neurons are affected and the processes of nerve-cells undergo degeneration and decay the mental reactions which are correlative to them also become impaired and tend to disappear.

As to the further explanation of the symptoms presented in alcoholic insanity, which may be either almost exclusively sensorial or almost exclusively intellectual, this must depend upon the implication of different cerebral territories in con. sequence of a selective action upon them of this poison, a selection controlled by the modifying factors which I have already referred to in different individuals; in some being restricted and limited, in others becoming widespread and far-reaching, owing to co-extensive vascular degeneration and sclerotic changes.

\section{Treatment of alcoholio Insanity.}

As to the treatment of cases of insanity due to the cause under consideration, but little need be said in regard to the withdrawal. The usual doctrine of removing the cause and the effect ceases, requires, however, in cases of alcoholism, some modification. The collapse occasionally resulting from the sudden withdrawal needs careful attention, as the 
persons in whom collapse occurs after withdrawal are pecu. liarly liable to pneumonia which, when failing to undergo resolution, ends in rapid phthisis. Such a termination is not uncommon in those cases of insanity due to drink which do not recover within one year. In the great majority of cases-indeed it might be said with but few exceptions-the total and sudden deprivation of alcohol is beneficial, but the mental relapses occurring in drink cases render the prospect of permanent cure among this class anything but encouraging. In many permanent recovery is hopeless to expect; in the rest it is uncertain, so that the great aim of treatment should be prophylactic-and here we enter upon an aspect which concerns the broader bearings of preventive medicine. I am of opinion that persons with a hereditary history of nervous diseases such as insanity, epilepsy, or hysteria, as also those in whom there is a direct hereditary history of intemperance, are best without alcohol altogether. How to control this class in regard to drink is a matter for the reformer, the statesman, and the philanthropist who recognise its pernicious social effects, for they listen to no counsel and spurn the best intentioned advice. Personally $I$ am a firm believer in the control exercised upon the sale of drink by restrictive legislation. I not only think, but know, that you can make not only men and women but villages and even larger communities sober by Act of Parliament; as witness the result of numerous measures tending to the limitation and to the regulation of facilities for the sale of intoxicating drinks. Measures tending to control disorder, which upon the unanimous report of the police is rampant when excessive facilities are afforded for the sale of drink, assist sobriety. Excessive facilities mean inefficient supervision and $I$ am informed that the London County Council has decided not to grant further licences in the area of the County Council unless two others are previously extinguished. I know personally the appreciation in respectable quarters among intelligent men and among working men themselves of the Sunday Closing Act in Wales. No doubt deficient opportunities to obtain alcohol tend to foster clandestine traffic and the establishment of drinking clubs, so that in. creased temperance is by no means in proportion to the reduction of public-houses. The trend of public opinion, not only in temperance circles but generally among working men, is to look upon drunkenness as a vice and a disgrace and to this we must look as a great controlling factor. Publicans themselves-although in many quarters looked upon as trading upon human infirmity -.-exercise a respect for the law which forbids serving children or drunken persons and these factors, together with the spread of education, social usage, increased facilities for healthy physical recreation and exercise, improved schemes for the sale of food and temperance drinks through the multiplication of such places as the "A B C" shops, the opening of public libraries, and the gen eral improved condition of life in regard to sanitation religion, and morality, all tend to sobriety and self-respect. I must also point out in regard to legislation which protects the brewer that a full exchequer and a drunken population are concomitants which will hardly be found to answer in the end, and while one chief source of revenue is encouraged the golden eggs may have cost us more than they are worth.

As to the use of inebriate homes, they afford a humanitarian method of suppressing those who abuse their freedom, and the benefits resulting from "retreats" are in direct, relation to the duration of residence; the longer the period of control the more the educative advantage. Cure in these establishments is neither attempted nor obtained.

It is sarcely possible, nor would it be profitable, to discuss the many vaunted nostrums for inebriety. The advertisement of them in the lay press is equivalent to an acknowledgment of their futility.

In conclution, although desirous of avoiding the "fallacy of extremes" in my own person. I am of opinion that the best working hypothesis for the prevention and cure of all forms of alcoholic disorders, whether mental or physical, must be that based upon the practice of total abstinence.

Claybury Asylum.

Merthyr Tydyil Hospital - Sir W. T. Lewis, Bart, has offered to contribute $£ 1000$ towards building a children's ward at the Merthyr Tydvil General Hospital, on condition that a similar amount is subseribed by the inhabitants of the town for the erection of a corresponding extension on the male :ide.

\section{A CASE OF EXTRA-TITERINE ASSOCIATED WITH INTRA-UTERINE FETATION IN WHICH ABDOMINAL SECTION WAS PERFORMED.}

\section{By JOHN PHILLIPS, M.A., M.D. CantaB., F.R.C.P.} LOND.,

OBSTETRIC PHYSICIAN TO KING'S COLLEGE HOSPITAL AND LECTURER ON PRACTICAL OBSTETRIOS IN KING'S COLLEGE; SENIOR PHYSTOIAN TO THE BRITISH IFENG-IN HOSPITAL.

ALTHOJGH great advance has reeently been made in our knowledge of the causation of extra uterine fetation much still remains to be elucidated. It is with this object that I have ventured to contribute the following case which appears to be of considerable rarity. Similar cases in the current literature of the subject have been analysed and the results appended.

The patient, a married woman, aged 28 years, had been twice confined but on each occasion prematurely at about the fifth or the sixth month of gestation. The last pregnancy terminated 12 months ago, the fœtus being dead and decomposed. Her catamenia were always regular and of the 31.day type and no pain or discomfort accompanied the flow, which was not excessive. Prior to her present illness she had gone for nearly six weeks without seeing anything and she considered herself pregnant. Seven weeks ago while lifting a bath she felt acute pain in the left side and hæmorrhage from the vagina set in and continued in varying degree until the date of operation. The practitioner who was first called to attend her found that several clots which had been passed had been thrown away, but he discovered the head of an eight-weeks fœetus in one of the diapers which had been used. When first seen by Dr. H. G. Ilott of Bromley on Dec. 12th, 1901, the patient was found to be pallid but well nourished and with dark hair and eyes. Her expression was pained and she referred her suffering to the left iliac fossa. A free bright red hæmorrhage was constantly going on from the vagina. On the 13th I saw her in consultation with Dr. Ilott. The abdomen was slightly distended and was tender, but no lump could be felt. The patient complained of severe pain on deep pressure in the left iliac fossa. Per vaginam much bloodstained mucus was noted as issuing from the cervix which was soft and admitted the examining finger up to the internal os uteri ; the uterus was bulky and pushed over to the right by a smooth, fixed globular swelling of the size of a large fist, which occupied the left and posterior quarter of the pelvis, encroaching somewhat, however, on the middle line. This lump was well defined, with an undulating surface over whieh no vessels could be felt pulsating. In consistence it was soft and elastic, giving the sensation rather of a dermoid cyst or soft myoma. The uterus was not freely mobile and there was a distinct sulcas between it and the lower portion of the swelling; the sound passed posteriorly and to the right two and three-quarter inches.

Under an anæsthetic the tumour was found to be very slightly mobile and not closely attached to the uterus. The vagina was thoroughly cleansed and an aspirator was pushed through the vaginal mucous membrane into the lump. The point of the instrument evidently passed into a cavity and some dark fluid blood escaped. The abdomen was opened in the usual situation. After passing through the integuments and faseia the peritoneum came into view; it was stained a brownish-purple colour. On npening the cavity several ounces of liquid blood and some dark black clots escaped. 'The patient was placed in Trendelenburg's position and the following conditions were noted. The great omentum was adherent to the parietal peritoneum through the lower half of its extent and was incised when the latter was opened; on passing the hand into the pelvis an adventitious sac was found, formed above and anteriorly by the great omentum, below by Douglas's pouch and the left nvarian fossa, laterally by the rectum with appendices epiploicæ, and anteriorly and below by the nterus. Half a coffee-cupful of dark blood clots was removed and a solid smooth ovoid mole of the size of a Tangerine orange was found among them. By means of an electric light the whole of the pelvic contents were seen; both tubes and ovaries were quite normal in appearan e and to touch, as also were the cacum and appendix. 